\title{
REFLECTION
}

\section{The Day I Died}

Julie M. Stausmire MSN, RN, ACNS-BC ${ }^{1}$

Mitchell G. Greenbaum DO, FACOOG ${ }^{2,3}$

Marie Morelli-Greenbaum, DO, FACOOG $^{2,3}$

'Mercy Health St. Vincent Medical Center, Toledo, Ohio

${ }^{2}$ Mercy Health St. Vincent Medical Center, Obstetrics \& Gynecology Residency

Program, Toledo, Ohio

${ }^{3}$ Mercy Health St. Charles Medical Center, Division of Obstetrics \& Gynecology, Oregon, Ohio

Conflicts of interest: authors report none.

\section{CORRESPONDING AUTHOR}

Julie M. Stausmire, MSN, RN, ACNS-BC Mercy Health St. Vincent Medical Center 2222 Cherry Street, MOB-2, Suite 1300 Toledo, $\mathrm{OH} 43608$

Julie_Stausmire@mercy.com

\begin{abstract}
When I began experiencing chest pain that was different from my usual heartburn symptoms, I denied I could possibly be having a heart attack, but chewed 4 baby aspirin just in case. Despite years of community education about the need to call 911 and seek immediate emergency care when experiencing signs and symptoms of a heart attack, more than 350,000 individuals experienced an out-of-hospital cardiac arrest in 2016. Of those, only $12 \%$ survived. Bystander recognition of cardiac arrest and prompt intervention with cardiopulmonary resuscitation (CPR) and rapid defibrillation is essential for out-of-hospital survival. Not everyone is fortunate enough to have the right people with the right equipment in the right place at the right time. I don't know why, but I was one of the lucky ones.
\end{abstract}

Ann Fam Med 2018;16:77-79. https://doi.org/10.1370/afm.2170.

W hile exiting the expressway on my way to perform scheduled surgical gynecology cases that morning, I came to a complete stop in the left-hand lane of the exit ramp with 3 cars ahead of me. The indigestion I had been experiencing overnight was different from the heartburn symptoms I'd had in the past. I declined my wife's suggestion to go to the emergency department, but compromised by taking 4 baby aspirin, and planned to follow-up with a previously scheduled appointment that afternoon with my internist. At the age of 53, on August 29, 2016 at approximately 7:40 AM, I died waiting for the traffic light to change.

I don't have any memory of the events surrounding my cardiac arrest, so this essay is based on the personal statements of the individuals who saved my life. Per the American Heart Association, the 2016 survival rate for adult non-traumatic, out-of-hospital cardiac arrests was only $12 \% .{ }^{1}$ I am very fortunate to be part of that lucky cohort.

After I arrested, my body slumped over towards the driver side window, restrained by the seat belt. Due to the latest in automotive technology, my car turns off when I brake and turns back on when I tap the gas pedal. My foot fell onto the gas pedal, and my full-size sport utility vehicle smashed into the car ahead of me, causing a chain of rear-end collisions. A school bus driver in the right-hand lane with a busload of students immediately notified 911 and later provided an eyewitness statement of the events to police investigators.

The driver of the first car, a former collegiate football player on his way to a job interview, heard a loud crash, and then a second crash. The car behind him was rocking forward and back in an odd pulsing motion. He was the first person to reach my car, which was on and engaged with the tires spinning. Looking through the window at me was eerie ${ }_{i}$ I wasn't moving, but I took a breath every once in awhile and then I just stopped breathing. My eyes were "open, unfocused, and unblinking, just blank, no life in them."

The driver of the car immediately ahead of me was a Desert Storm veteran surgeon with whom I worked. He also heard the SUV accelerate, and instinctively activated the emergency brake to try to avoid hitting the car ahead. My vehicle kept relentlessly ramming his and pushed his car under 
the bumper of the car ahead of him. The surgeon's first thought was I was probably texting and not paying attention until he looked in his rearview mirror and saw me slumped over. He came back to my car and immediately recognized me through the window, called my name, and began yelling that he needed something to break the window and get me out of the car.

The driver of the second car, a pharmaceutical representative, handed over a wooden baton. On the second attempt to smash open the rear driver side window, the safety glass only rippled while the club disintegrated. He returned with a tire iron.

The driver of the car next to me, a local high school administrator, was banging on the passenger side window, trying unsuccessfully to rouse me and to open the locked doors. He had recently completed an ALICE (Alert, Lockdown, Inform, Counter, Evacuate) training, ${ }^{2}$ a course on how to proactively handle the threat of an aggressive intruder or active shooter event in a school setting. Remembering those teachings on how to break windows by striking the corner of the window, not the center, and using the tire iron, the glass shattered. During this entire rescue attempt, my car was still in gear with my foot on the gas, with the wheels spinning and the vehicle still trying to push forward against the cars ahead of it. My rescuers put their own lives in danger trying to save mine.

The football player cleared most of the glass but was unable to locate the lock to open the back door. He reached through the window, cutting his arm and hand, but couldn't get to the lock. Using the tire iron, he reached around me and pushed open the door lock.

All 4 rescuers worked together to unbuckle my seatbelt, shove my leg off the gas pedal, turn the car off, lift me out of the car, and lay me down on the side of the road.

The surgeon checked for a pulse but there was none. He immediately started compression-only cardiopulmonary resuscitation (CPR). A police vehicle arrived on the scene first, providing the rescuers with a pocket mask and an automated external defibrillator (AED). The surgeon connected the AED, delivered the first shock, then resumed compressions. The football player, who had taken a community CPR class, began giving me breaths with the pocket mask. I was shocked a 2nd time with the AED followed by more CPR. A basic life support crew and the fire chief arrived on scene, followed almost immediately by the advanced cardiac life support rescue squad. They took over CPR and placed a ResQPump on my chest. ${ }^{3.6}$ This device looks like a giant suction cup with a double handle on top that is placed on the middle of the sternum. The REesQPump enhances CPR, allowing rescuers to push down for chest compressions and actively re-expand the chest by pulling up during the decompression phase. This augmentation of negative intrathoracic pressure increases perfusion of the heart and brain. They continued ventilations with a bag valve/mask device and high flow oxygen instead of the pocket mask at a ratio of 30 compressions: 2 ventilations.

The fire chief removed the AED and connected me to a monitor/defibrillator unit, verified I was in ventricular fibrillation, and delivered a 3rd unsuccessful shock. Finally, on the 4th defibrillation attempt, my cardiac rhythm converted from ventricular fibrillation to a sinus rhythm with return of spontaneous circulation. A 12-lead electrocadiogram demonstrated evidence of a huge ST segment elevation myocardial infarction (STEMI). After placement of an intravenous line and continued manual ventilation for agonal breaths, the surgeon urged the squad to not try to intubate me on the scene and delay my transfer to a heart center. He stressed they immediately take me to the level-one trauma \& comprehensive stroke center with a cardiac catheterization lab 4 miles away instead of the local community hospital, which had none of these resources, and where I was supposed to be doing my 6 scheduled surgeries.

Not surprisingly, I became increasingly agitated and combative during the transport as a result of the hypoxic-ischemic brain injury sustained during the arrest. Upon arrival to the emergency department I was met by both the emergency medicine and trauma surgery attending physicians who sedated, paralyzed, and intubated me. The verbal handoff from the paramedics was very brief and described several differentials including a possible stroke or seizure prior to a motor vehicle collision that precipitated the cardiac arrest with bystander CPR and defibrillation. The emergency department team considered 2 possible clinical pathways - anticoagulate me and go directly to the cardiac catheterization lab where the cardiologist was waiting; or go to radiology for a computed tomography scan of the brain? Choosing the wrong pathway could be a fatal mistake. My wife, also an OBGYN physician, arrived and related my earlier episode of chest pain and the decision was made to go to the catheterization lab.

The cardiac catheterization demonstrated I had a $100 \%$ blockage of the left main anterior descending artery as well as 4 other significant blockages. The cardiologist inserted a balloon pump, the cardiothoracic surgeon cleared an operating room, and I was in surgery for a quintuple bypass followed by post cardiac arrest therapeutic hypothermia (aka targeted temperature management) in the intensive care unit for over 48 hours. After 10 days in the hospital, I was discharged to a rehabilitation unit for a week before going home 
wearing a Life Vest Defibrillator ${ }^{7-10}$ for the first 6 weeks. Eight weeks after I died, I returned to work with no neurological deficits.

I have been asked about any near-death experience. For me it was like going to sleep and not dreaming-I remember being awake, then nothing, then awake again. I don't remember the 2 days prior to my cardiac arrest and have only a few brief images of being in the hospital, with most of my memory returning in the rehab unit. Oddly enough, I don't feel badly about not seeing any tunnels of light or loved ones waiting for me-I am okay knowing it was just a "lights out" with no pain.

Like many others who have been in a life-or-death situation, I walked away thankful for more time to be with my wife and children, and determined to help prevent other families from losing a loved one. As a physician and an OBGYN residency program director at a tertiary level-1 trauma center, I have a unique opportunity to directly impact women's cardiac health. My population base is women. Per the American Heart Association, heart disease kills 1 out of 3 women, vs breast disease which kills 1 out of 31 women. Heart disease is the number 1 cause of death in women, yet only 1 in 5 American women believe that heart disease is a health threat. ${ }^{11}$ Women are less likely to call 911 , frequently because they do not exhibit the traditional symptoms of chest pain typically experienced by men and don't believe they are experiencing a heart attack. ${ }^{11}$

My survival allows me a unique opportunity to stress the importance of preventative care as well as the need to seek emergent care for women and their male partners/family/friends. My private practice has always focused on the holistic health of women. For clinicians who see opportunities for improvement in their own practices, the AHA has sponsored the Go Red For Women Campaign for years. Their website has a wide variety of health care professional tools and resources that can easily be incorporated into any setting. ${ }^{11}$

As the director of a residency program, I have the ability to mentor physicians in training to look beyond the pap test or the mammogram. Our residents rotate to my private practice, allowing them time to perfect a holistic approach that is not always possible in the residency ambulatory clinic setting. As newly trained physicians going into their own practices, they need to embrace their role as primary care providers for the many women whose only health care provider may be their OBGYN.

For cardiac arrest victims, every second is critical to survival. Statistically I should have died in my car or survived with severe permanent neurological deficits. I cannot thank enough all of the people who worked together to save my life, especially the bystanders at the scene who got me out of the car and started CPR so quickly. Whenever possible, we need to recognize these community heroes who sometimes put their own lives at risk to save others. Many communities, including mine, offer annual recognition events of Good Samaritans, and I have nominated each of the individuals who played a role in my survival for an award. I have met or talked with most of them. They relate the impact this has had on their lives; an incredible sense of being put in the right place at the right time with the right people to truly make a difference in someone else's life. In my case, these bystanders' willingness to step up really did save my life.

To read and post commentaries in response to this article, see it online at http://www.AnnFamMed.org/content/16/1/77.

Submitted February 20, 2017; submitted, revised, June 13, 2017; accepted July 19, 2017.

Key words: Out-of-hospital-cardiac arrest; physician; bystander CPR; ResQPump; automated external defibrillator; work-life balance

This manuscript has not been previously published or disseminated at professional conferences.

\section{References}

1. Statistical update: 2016 out-of-hospital cardiac arrest. American Heart Association website. http://www.cpr.heart.org/AHAECC/ CPRAndECC/General/UCM_477263_Cardiac-Arrest-Statistics.jsp. Accessed Jun 9, 2017.

2. ALICE Training Institute website. https://www.alicetraining.com/. Accessed Jun 9, 2017.

3. FDA approves CPR devices that may increase chance of surviving cardiac arrest [FDA News Release]. US Food and Drug Administration website; March 9, 2015. http://www.fda.gov/NewsEvents/ Newsroom/PressAnnouncements/ucm437247.htm. Accessed Jun 9, 2017.

4. Frascone RJ, Wayne MA, Swor RA, et al. Treatment of non-traumatic out-of-hospital cardiac arrest with active compression decompression cardiopulmonary resuscitation plus an impedance threshold device. Resuscitation. 2013;84(9):1214-1222.

5. CardioPump (aka ResQPump). Advanced Circulatory Systems, Inc website. http://www.resqpod.com.au/cardiopump.htm. Accessed Jun 9, 2017.

6. Debaty G, Metzger A, Lurie K. Evaluation of Zoll Medical's ResQCPR System for cardiopulmonary resuscitation. Expert Rev Med Devices. 2015;12(5):505-516.

7. What is the Life Vest Wearable Defibrillator? Zoll website. https:// www.lifevest.zoll.com/medical-professionals. Accessed Jun 9, 2017.

8. Klein HU, Goldenberg I, Moss AJ. Risk stratification for implantable cardioverter defibrillator therapy: the role of the wearable cardioverter-defibrillator. Eur Heart J. 2013;34(29):2230-2242.

9. Kutyifa V, Moss AJ, Klein H, et al. Use of the wearable cardioverter defibrillator in high-risk cardiac patients: data from the Prospective Registry of Patients Using the Wearable Cardioverter Defibrillator (WEARIT-II Registry). Circulation. 2015;132(17):1613-1619.

10. Chung MK. The role of the wearable cardioverter defibrillator in clinical practice. Cardiol Clin. 2014;32(2):253-270.

11. Causes and prevention of heart disease. American Heart Association website. https://www.goredforwomen.org/about-heart-disease/ facts_about_heart_disease_in_women-sub-category/causesprevention/. Accessed Jun 7, 2017. 